\title{
Natural Yield Curve: The Case of Indonesia
}

Yoga Affandi, Berry A. Harahap, Pakasa Bary, Fenty T. Suryani

\begin{abstract}
The purpose of this study is to estimate the natural yield curve for an emerging economy, with Indonesia as a case study. The estimation is done by a two-stage approach, namely, the decomposition of the yield curve component through a dynamic Nelson-Siegel model, the results of which are then used to estimate a natural yield curve. Both steps are estimated through state space modeling with a Kalman filter. In addition, the study also analyzes the principal components of the real yields of Indonesia to prove that the use of the Nelson-Siegel model is relevant and sufficient. The main contribution of this research is the estimation of the natural yield curve for an emerging economy. The findings provide some evidence that a policy mix is needed for emerging economies to maintain macroeconomic stability. Some other findings are as follows: first, almost all yield curve variations can be explained by the first three principal components that moved similarly to level, slope, and curvature. Second, Indonesia's natural yield curve always has a positive slope over time. Third, across maturities, medium-term yields have the largest impact on the output gap. Fourth, the estimated natural yield curve can provide a gauge of the monetary policy stance, or external pressure.
\end{abstract}

KEY WORDS: $\quad$ term structure, yield curve, natural interest rate, monetary policy, Kalman Filter.

JEL Classification: C32, E43, E52.

Economic and Monetary Policy Department, Bank Indonesia, Indonesia

\section{Introduction}

Since the global financial crisis in 2008, the world economy continues to be plagued by uncertainty. To prevent the recurrence of the Great Depression, some of the world's major central banks adopted unconventional monetary policies that increase market liquidity and financial stability risks. The big challenge for policymakers, particularly in emerging markets, is how to moderate the impact of global monetary and financial policies on the domestic economy. A good policy can offset the negative effects of an external shock while also benefiting from the advantages of an open econ-

Correspondence concerning this article should be addressed

to: Pakasa Bary, Economic and Monetary Policy Department, Bank Indonesia, Indonesia. E-mail: pakasa_b@bi.go.id omy. Yet, this requires taking into account two major factors: the global transmission channels and the presence of two trilemma.

Transmission of external shocks to the domestic economy can occur through at least three channels: trade, terms of trade, and financial channels. In addition, there is also a confidence channel that affects the smoothness of these three channels. A declining commodity price affects Indonesia's external and fiscal posture via trade channels. Through financial channels, China's stock market turbulence may pose a different risk compared to the effects of the U.S. taper tantrum in 2013. According to Harahap et al.. (2016), the risk of a decline in Indonesia's economic growth due to the Fed's policy is primarily transmitted via financial channels, while China's turbulence may be transmitted 
through trade channels.

Financial globalization creates two trilemma. The first trilemma is a monetary trilemma, which states that no country can achieve three macroeconomic targets (free capital flows, exchange rate stability, and monetary policy independence) at once. The second trilemma is a financial trilemma, where financial stability, financial integration, and prudential policy cannot be achieved simultaneously (Schoenmaker, 2011). When financial markets are integrated globally, a country must choose either financial stability or financial policy independence.

Currently, there are three views in the international economy: The first view advocates that monetary authorities should focus on the price stability objective and allow exchange rates to float freely (Woodford, 2011). The second view asserts that many developing countries do not de facto apply a free float regime because of the significant effects on prices and output (Calvo \& Reinhart, 2012), so a form of capital flow restrictions, such as macroprudential policy, needs to be applied to face the global financial cycle (Rey, 2013). The third view, a moderate one, is conveyed by Obstfeld (2014) and states that independent monetary policy is possible in countries that are financially open, but the influence of monetary policy may be more limited in such countries.

Obstfeld (2014) further explains that countries adopting flexible exchange rate regimes still have monetary autonomy in the short term, although long-term interest rates are more influenced by external factors. The central bank still has the capacity to direct the economy, and short-term interest rate changes reflect responses to changes in domestic variables (such as inflation and output) but not to changes in external variables (such as U.S. interest rates). This is also in accordance with the findings of Harahap et al. (2013) in which the policy rate significantly affects inflation, although transmission is slightly affected by excess liquidity after the global financial crisis. Therefore, the term structure is a very important consideration for monetary policy. Several previous studies have been conducted to analyze the term structure or yield curve in Indonesia, including Djuranovik (2014) and Harahap et al. (2014), among others.
In the macroeconomic management order, to support long-term economic growth without the risk of excessive inflation, the average short-term interest rate needs to be directed to fit the natural interest rate (Basdevant et al., 2004). Therefore, knowing the level of neutral interest rates is important for formulating monetary policy. Some studies which estimated the natural interest rate in Indonesia include Nugroho and Mochtar (2006) and Wimanda et al. (2013). However, in monetary policy implementation, one of the remaining questions is how to translate the natural interest rate to operational instruments with several different maturities. In addition, as explained in Imakubo et al. (2018), yields on all maturities altogether indicates the actual monetary policy stance.

Based on these considerations, the analysis of term structure and the natural interest rate is not enough if done separately. It takes research that can answer the natural interest rate on every maturity in the term structure (i.e., the natural yield curve), Brzoza-Brzezina and Kotłowski (2014) and Imakubo et al. (2018) are pioneering previous studies on the estimation of the natural yield curve that use data from the U.S. and Japan, respectively.

This paper will contribute to the literature by providing an estimation of the natural yield curve for Indonesia, an emerging economy. To our knowledge, this is the first attempt to estimate the natural yield curve for Indonesia, as well as for an emerging economy. Estimating the yield curve and the neutral rate for longer maturities is especially important in emerging economies, as they are more prone to external shocks than advanced economies. The result is in line with the former attempts on advanced economies, and therefore indicate robustness of the method, and its applicability on emerging markets as well. In addition, the policy discussion adds some policy implications related to the estimated slope and curvature difference between natural and real yield curve.

The remainder of this paper is organized as follows. The second section discusses the literature review of natural interest rates, term structures, and natural yield curves. The third section explains the methodology, followed by the results and discussion in section four. Section five concludes the paper. 


\section{Literature Review}

\subsection{Natural Interest Rates}

The concept of natural interest rates has been discussed for more than 100 years, with uptrends and downswings in popularity (Brzoza-Brzezina \& Kotłowski, 2014). The reemergence of the natural rate of interest concept in recent decades is related to the introduction of inflation targeting by some of the leading central banks in the 1990s. In an inflation targeting regime, the monetary authority controls short-term interest rates in order to stabilize inflation according to its target. As a consequence, the concept of short-run rate equilibrium, which stabilizes the economy, receives much attention from both the theoretical and empirical points of view (Laubach and Williams, 2003).

According to Wimanda et al. (2013), the natural rate of interest helps policymakers decide whether an interest rate tends to be contractionary or expansionary. Nonetheless, the natural rate of interest does not necessarily provide an interest rate that must be used with certainty. To determine whether the interest rate is expansionary or contractionary, policy makers need to weigh various other factors, such as inflation persistence and trade-offs among macroeconomic variables.

Although it attracts a lot of attention, the natural rate of interest has some limitations. First, the natural rate of interest is an unobserved variable with all the consequences of measurement and uncertainty estimates. While this does not diminish its appeal as a theoretical concept, it can undermine its practical use by policymakers (Orphanides \& Williams, 2007). Second, the natural rate of interest always creates confusion about the maturity at which the interest rate should be applied. According to Wicksell, the natural rate is a long-term concept (Amato, 2005). However, most new studies approach the natural rate of interest from a short-term perspective in line with the operational target of many central banks.

The challenge to recover after the global financial crisis changed the way the central bank saw their policy instruments. Some major central banks decided to do what is known as unconventional monetary policy. One example is the quantitative easing introduced by the Fed, where the important goal is to lower longterm interest rates. This means that the central bank is undertaking a non-traditional policy to directly influence the yield curve. Blinder et al. (2008) explain that the impact of the central bank on long-term interest rates has been announced since the financial crisis, even before forward guidance was actively used to influence yield curves.

\subsection{Term Structure}

The relationship between interest rates on bonds with different maturities is called the term structure of the interest rate, which is overall described as a yield curve. The yield curve may reflect market expectations for future interest rates, which further reflect economic conditions. The yield curve is generally upward sloping with convex curvature. The yield curve may also be downward sloping, but this usually only occurs temporarily.

The yield curve form has been described by several theories, including pure expectations theory, liquidity preference theory, and preferred habitat theory. Pure expectations theory assumes that the slope of the yield curve only reflects investors' expectations for shortterm interest rates in the future. Liquidity preference theory explains that the difference in yield between maturities is also due to the risk premium among maturities, as there is an added risk in holding longerterm debt securities. Preferred habitat theory explains that investors have a preference maturity in holding bonds, which will affect the yield on certain maturities relative to other maturities. Associated with preferred habitat, there is a relatively new theory of market segmentation, where because of the different preference of maturities, the bonds with different maturities are not easily substituted. As a result, yield curves are formed on demand and supply conditions in each maturity.

A number of approaches have been developed that allow modeling of the yield curve as a function of several parameters. This is based on affine models and yield curve decomposition. Affine models were originally built by Duffie and Kan (1996) and later developed by Duffee (2002). The affine term model structure describes the interest rate as a linear combination of a small number of factors and parameters by using non-arbitrage restrictions.

A number of previous studies related to affine models evaluated the principal components of the yields of each tenor as a function of each yield on the 
term structure. The general finding is that the first three principal components of the yield have a unique shape known as the level, slope and curvature, as can be seen in Cochrane and Piazessi (2005). Levels have the same contribution to all maturities, slope makes a major contribution to short-term maturities, and curvature makes a major contribution to medium-term maturity.

The representation of the principal components in simple functional representation can be done by the second approach (i.e., the yield curve decomposition, proposed by Nelson and Siegel (1987) and further developed by Svensson (1995) and Christensen et al. (2009). The Nelson-Siegel (1987) approach allows simple yield curve drawing with a small number of latent factors, which can represent the three main factors of yield curve (i.e., level, curvature, and slope). Diebold and $\mathrm{Li}$ (2006) later introduced a time-varying latent factors version of the Nelson-Siegel decomposition.

\subsection{Natural Yield Curve}

Combining the concept of the natural rate of interest and the term structure produces the natural yield curve. The concept of the natural yield curve, as described by Brzoza-Brzezina and Kotłowski (2014) and Imakubo et al. (2018), is based on the Laubach and Williams (2003) model, which is widely used to measure the natural rate of interest. In this natural yield curve model, the relationship between the interest rate gap and the output gap is given by the IS curve:

$y_{t}-y_{t}^{*}=b\left(r_{t}-r_{t}^{*}\right)$

where $y_{t}$ denotes the $\log$ of the actual output, $y_{t}^{*}$ denotes the log of the potential output, $r_{t}$ denotes the actual interest rate, and $r_{t}^{*}$ denotes the natural rate of interest. The output gap and interest rate gap are determined by $y_{t}-y_{t}^{*}$ and $r_{t}-r_{t}^{*}$. respectively. From equation (1), it is clear that $y_{t}-y_{t}^{*}=0$ if $r_{t}-r_{t}^{*}=0$ This means that $r_{t}^{*}$ is the real interest rate in which the economic state is equal to its potential level, or is neither inflationary nor deflationary. Laubach and Williams (2003), using the Kalman filter method, estimate unobservable variables, i.e., $r_{t}^{*}$ and $y_{t}^{*}$, based on observation equations - the IS curve in equation (1) and the Phillips curve - and state equations for $r_{t}^{*}$ and $y_{t}^{*}$.
As explained in Imakubo et al. (2018), the concept of the natural rate of interest is extended from that defined in a single maturity to all maturities. In particular, the relationship between the interest rate gap at the time of a single maturity and the output gap in equation (1) is modified to represent the relationship between the interest rate gap for all maturities $0<\tau<$ $T$ and the output gap, which results in the following:

$y_{t}-y_{t}^{*}=b \int_{0}^{T} \phi(\tau)\left(r_{\tau, t}-r_{\tau, t}^{*}\right) d \tau$

where $r_{\tau, t}$ and $r_{\tau, t}^{*}$ are the actual real interest rates for maturity $\tau$ at time $t$, and the natural rates of interest for maturity $\tau$ at time $t$. For simplification, let $\left\{r_{\tau, t}^{*}\right\}_{\tau=0}^{T}$ and $\left\{r_{\tau, t}\right\}_{\tau=0}^{T}$ be the natural yield curve and the actual real yield curve, respectively. $\phi(\tau)$ is a parameter that explains the difference in the sensitivity of the output gap, $y_{t}-y_{t}^{*}$, to the interest rate gap at each maturity, $r_{\tau, t}-r_{\tau, t}^{*}$. It is defined as $\phi(\tau) \geq 0$ for all $\tau$ and $\int_{0}^{T} \phi(\tau) d \tau \equiv 1$.

The two $\left\{r_{\tau, t}^{*}\right\}_{\tau=0}^{T}$ and $\left\{r_{\tau, t}\right\}_{\tau=0}^{T}$ can be decomposed into the three latent factors described in the Nelson and Siegel models (1987). Thus, the interest rate of each maturity on the yield curve is given by a combination of these three factors, with a formal representation as follows:

$$
\begin{aligned}
& r_{\tau, t}^{*}=L_{t}^{*}+S_{t}^{*} \frac{1-e^{-\lambda t}}{\lambda \tau}+C_{t}^{*}\left(\frac{1-e^{-\lambda t}}{\lambda \tau}-e^{-\lambda t}\right) \\
& r_{\tau, t}=L_{t}+S_{t} \frac{1-e^{-\lambda t}}{\lambda \tau}+C_{t}\left(\frac{1-e^{-\lambda t}}{\lambda \tau}-e^{-\lambda t}\right)
\end{aligned}
$$

where $\lambda$ is the parameter that corresponds with the decaying rate of the slope and curvature components. Imakubo et al. (2018) assume that the natural yield curve and the actual yield curve have the same $\lambda$.

$L_{t}^{*}, S_{t}^{*}$ and $C_{t}^{*}$ are the natural yield curve components. $L_{t}^{*}$ in equation (3) is the level factor, which explains the level of the natural yield curve and uniformly affects the entire time of maturity. If $L_{t}^{*}$ increases, then the natural yield curve shifts upward and vice versa.

$S_{t}^{*}$ in the second term is the slope factor, which explains the slope of the natural yield curve and corresponds to the term spread of the natural yield curve. $S_{t}^{*}<0$ indicates an upward sloping curve, $S_{t}^{*}>0$ indicates a downward sloping curve, and $S_{t}^{*}=0$ indicates a flat curve. $C_{t}^{*}$ in the third term is the curvature factor, which explains the curvature of the natural yield curve. $C_{t}^{*}<0$ indicates that the curve of the natural yield curve bends downward and vice versa. Similarly, $L_{t}$, 
$S_{t}$, and $C_{t}$ in equation (4) can be interpreted as the level, slope, and curvature factors of the actual yield curve.

Subtracting equation (3) from equation (4) yields:

$$
\begin{aligned}
& r_{\tau, t}-r_{\tau, t}^{*}=\left(L_{t}-L_{t}^{*}\right)+\left(S_{t}-S_{t}^{*}\right) \frac{1-e^{-\lambda \tau}}{\lambda \tau} \\
& +\left(C_{t}-C_{t}^{*}\right)\left(\frac{1-e^{-\lambda \tau}}{\lambda \tau}-e^{-\lambda \tau}\right)
\end{aligned}
$$

For all $\tau$. The equation shows that the yield curve gap can be decomposed into three components: level gap, $L_{t}-L_{t}^{*}$; slope gap, $S_{t}-S_{t}^{*}$; and curvature gap $C_{t}-C_{t}^{*}$. Hence, those three components are related to monetary policy.

Substituting equation (5) for equation (2) yields:

$$
\begin{aligned}
& y_{t}-y_{t}^{*}=b_{L}\left(L_{t}-L_{t}^{*}\right)+b_{S}\left(S_{t}-S_{t}^{*}\right) \\
& +b_{C}\left(C_{t}-C_{t}^{*}\right)
\end{aligned}
$$

where

$$
\left\{\begin{array}{c}
\frac{b_{L}}{b}=\int_{0}^{T} \emptyset(\tau) d \tau=1 \\
\frac{b_{S}}{b}=\int_{0}^{T}\left\{\varnothing(\tau) \frac{1-e^{-\lambda t}}{\lambda t}\right\} d \tau \\
\frac{b_{C}}{b}=\int_{0}^{T}\left\{\varnothing(\tau)\left(\frac{1-e^{-\lambda t}}{\lambda t}-e^{-\lambda t}\right)\right\} d \tau
\end{array}\right.
$$

Note that the interest rate gap in each maturity, $r_{\tau, t}-r_{\tau, t}^{*}$, in equation (2) is replaced by a level gap, $L_{t}-L_{t}^{*}$; slope gap, $S_{t}-S_{t}^{*}$; and curvature gap, $C_{t}-C_{t}^{*}$. If $L_{t}-L_{t}^{*}=S_{t}-S_{t}^{*}=C_{t}-C_{t}^{*}=0$, which implies that $r_{\tau, t}-r_{\tau, t}^{*}=0$ for every $\tau$, then $y_{t}-y_{t}^{*}=0$ is obtained. Similar to the natural interest rate, the natural yield curve is defined as a real yield curve when the economy is neither inflationary nor deflationary.

\section{Methodology}

\subsection{Model}

Currently, there are two methods to estimate the natural yield curve. The first method was used by BrzozaBrzezina and Kotłowski (2014). The second method was employed by Imakubo et al. (2018). The Brzoza-Brzezina and Kotłowski method (2014) assumes that the level gap $\left(\mathrm{L}_{-} \mathrm{t}-\mathrm{L}_{-} \mathrm{t}^{\wedge *}\right)$ is zero and the curvature component of the natural yield curve is time-invariant. However, the
Imakubo et al. (2018) method is more flexible because it does not impose both restrictions. Thus, the Imakubo et al. (2018) model has the advantage of explaining the sensitivity of an economy to each of the yield curve components, as well as the difference in the term structure between the real yield curve and the natural yield curve. Therefore, this paper applies the natural yield curve calculation as implemented by Imakubo et al. (2018).

The approach is divided into two stages: First, the estimation of the yield curve components using the Dynamic Nelson-Siegel (DNS) method according to Diebold et al. (2006), which is a dynamic version of the yield curve approach of Nelson and Siegel (1987); and second, the estimation of the natural yield curve to convert the real yield curve components into natural yield curve components. Technically, both stages use the state-space estimation method with a Kalman filter.

This paper considered modifying the method of Imakubo et al. (2018) by using the yield curve decomposition of Svensson (1995) with four latent variables. However, the decomposition with four latent variables has the potential to cause two humps. In a country such as Indonesia that has rather limited financial development, market imperfections in some maturities are more likely. In other words, when applied to an Indonesian dataset, the method is more susceptible to market imperfections and other distortions relative to maturity, making it less relevant to the measurement of fundamental variables, such as the natural yield. Therefore, this paper still uses a decomposition with three latent variables.

As an additional justification for the use of a particular yield curve decomposition method, this study will initiate analysis by briefly conducting principal component analysis on the Indonesian real yield curve, as well as residual analysis of the regression of the first three principal components. In the analysis, the principal component is useful to show the main component pattern of the yield curve, and to show decomposition with three latent variables is sufficient for analysis. Principal component analysis in modeling factors affecting the yield curve has often been used previously (e.g., by Cochrane \& Piazessi, 2005).

After principal component analysis, the estimations of the yield curve based on the dynamic Nelson-Siegel and natural yield curve are conducted. Based on Imakubo et al. (2018), for estimation purposes, it is neces- 
sary to add to the dynamic model by modifying equation (6) by adding the lag output gap $y_{t-1}-y_{t}^{*}$ . In addition, the yield curve gap component is assumed to follow an $\mathrm{AR}(1)$ process. In matrix form, the representation is as follows:

$\left[\begin{array}{l}y_{t} \\ L_{t} \\ S_{t} \\ C_{t}\end{array}\right]=\left[\begin{array}{l}y_{t}^{*} \\ L_{t}^{*} \\ S_{t}^{*} \\ C_{t}^{*}\end{array}\right]+\left[\begin{array}{cccc}a_{y} & b_{L} & b_{S} & b_{C} \\ 0 & a_{L} & 0 & 0 \\ 0 & 0 & a_{S} & 0 \\ 0 & 0 & 0 & a_{C}\end{array}\right]\left[\left(\begin{array}{c}y_{t-1} \\ L_{t-1} \\ S_{t-1} \\ C_{t-1}\end{array}\right)-\left(\begin{array}{c}y_{t}^{*} \\ L_{t}^{*} \\ S_{t}^{*} \\ C_{t}^{*}\end{array}\right)\right]$

$+\left[\begin{array}{cccc}1 & 0 & 0 & 0 \\ g_{y L} & 1 & 0 & 0 \\ g_{y S} & 0 & 1 & 0 \\ g_{y C} & 0 & 0 & 1\end{array}\right]\left[\begin{array}{c}\varepsilon_{t}^{y} \\ \varepsilon_{t}^{L} \\ \varepsilon_{t}^{S} \\ \varepsilon_{t}^{C}\end{array}\right]$

Aside from the output variables and yield curve components, the last brackets on both equations are error terms, and the rest are constant parameters.

In the first stage, the Dynamic Nelson-Siegel (DNS) method, as described in Diebold et al. (2006), is performed to obtain the real level component $\left(L_{t}\right)$, real slope $\left(S_{t}\right)$, and real curvature $\left(C_{t}\right)$. Estimates are based on an observation equation as follows:

$r_{\tau, t}=L_{t}+S_{t}\left(\frac{1-e^{-\lambda \tau}}{\lambda \tau}\right)+C_{t}\left(\frac{1-e^{-\lambda \tau}}{\lambda \tau}-e^{-\lambda \tau}\right)+\varepsilon_{\tau, t}$

And a state (transition) equation as follows:

$\left[\begin{array}{l}L_{t}-\mu_{L} \\ S_{t}-\mu_{S} \\ C_{t}-\mu_{C}\end{array}\right]=\left[\begin{array}{lll}a_{11} & a_{12} & a_{13} \\ a_{21} & a_{22} & a_{23} \\ a_{31} & a_{32} & a_{33}\end{array}\right]\left[\begin{array}{c}L_{t-1}-\mu_{L} \\ S_{t-1}-\mu_{S} \\ C_{t-1}-\mu_{C}\end{array}\right]+\left[\begin{array}{c}\epsilon_{t}^{L} \\ \epsilon_{t}^{S} \\ \epsilon_{t}^{C}\end{array}\right]$

where $r_{\tau, t}$ is the real interest rate for maturity $\tau$ at $t$. $\lambda$ is a decaying factor. $\epsilon_{t}^{L}, \epsilon_{t}^{S}$, and $\epsilon_{t}^{C}$ are error terms. $L_{t}, S_{t}$, and $c_{t}$ follow a VAR (1) process with mean $\mu_{L}, \mu_{S}$, and $\mu_{C}$, respectively. $\varepsilon_{\tau, t}$ and $\epsilon_{t}^{j}$ for $j=L, S, C$ are normally distributed. $\epsilon_{t}^{j}$ is correlated but $\varepsilon_{\tau, \mathrm{t}}$ is independent and uncorrelated with $\epsilon_{t}^{j}$.

In the second stage, an estimate of the natural yield curve is performed to obtain the natural yield curve (i.e., $L_{t}^{*}, S_{t}^{*}$ and $C_{t}^{*}$ ). Following Imakubo et al. (2018), the estimation is done through an observation equation as follows:

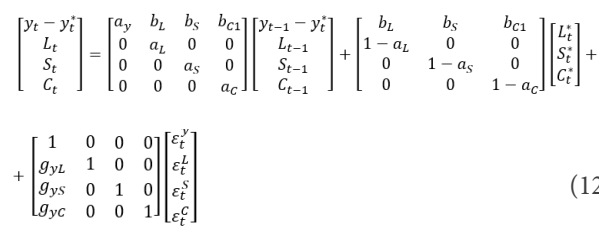

And a state (transition) equation as follows:

$\left[\begin{array}{c}L_{t}^{*} \\ S_{t}^{*} \\ C_{t}^{*}\end{array}\right]=\left[\begin{array}{c}L_{t-1}^{*} \\ S_{t-1}^{*} \\ C_{t-1}^{*}\end{array}\right]+\left[\begin{array}{c}h_{y L} \\ h_{y S} \\ h_{y C}\end{array}\right] \varepsilon_{t}^{\Delta y^{*}}+\left[\begin{array}{ccc}1 & 0 & 0 \\ h_{L S} & 1 & 0 \\ h_{L C} & h_{S C} & 1\end{array}\right]\left[\begin{array}{c}\varepsilon_{t}^{L^{*}} \\ \varepsilon_{t}^{S^{*}} \\ \varepsilon_{t}^{c^{*}}\end{array}\right]$

An additional assumption that is specific to the statespace model is the absence of correlation between errors. Both estimation steps are performed using state-space with a Kalman filter. For initial values, the numbers are based on economic theory, Imakubo et al. (2018) estimation results, and dynamic stability requirements.

\subsection{Data}

This study uses the yield of government bonds for nominal interest rate data over a monthly period from 2005 to 2015. All data are obtained through Bloomberg. Following one of the functional forms used by Wimanda et al. (2013), real interest rates are calculated through hybrid backward- and forwardlooking inflation expectations as follows:

$r_{\tau, t}=i_{\tau, t}-\alpha \pi_{t-1}-(1-\alpha) \pi_{t}^{*}$

where $\pi_{t-1}$ and $\pi_{t}^{*}$ are the lag inflation and inflation target at time t, respectively. $r_{\tau, t}$ and $i_{\tau, t}$ are the real and nominal interest rates for maturity $\tau$ at time $t$, respectively. $\alpha$ is a constant parameter where $0<\alpha<1$.

The output gap data are obtained through Bank Indonesia and are computed by a multivariate filter. The assumption in output gap estimation, especially related to interest rates, is consistent with the dataset used in this paper. While it is possible to obtain an output gap series directly from the natural yield curve model by treating potential output as a state variable, it is difficult to obtain a consistent result for all state variables with that strategy. In addition, estimating output gap is not the main objective of this paper. Therefore, this paper follows Imakubo et al. (2018) to treat output gap data as given. 
Some robustness tests are also conducted using Consensus Forecast's inflation expectations instead of inflation targets, and using output gap data derived from a one-sided HP Filter. The estimation results for both alternatives are very close to the main estimation results that are reported on this paper.

The real yield term structure data are generated in this study and will be used for the estimation process, as illustrated in Figure 1. In general, Indonesia's real term structure has a substantial difference between short yield maturity and long maturity, although in the data for approximately a decade, a mean-reverting process provided average real yields in the range of $0-4 \%$. The movements seen in Figure 2 are only common factors because all maturity has the same movement.

\section{Results and Discussion}

Principal component analysis suggests that the first three principal components are consecutively shaped like a level, slope, and curvature (Figure 2).

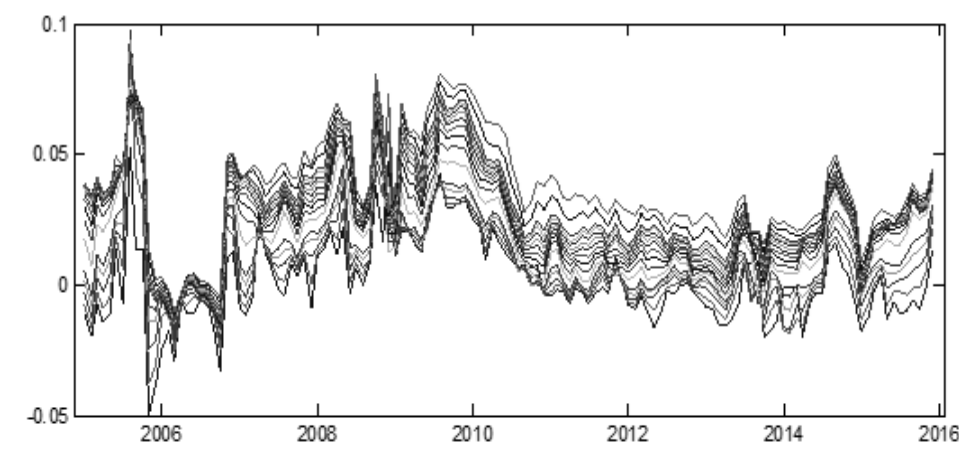

Figure 1. Real yields by maturity.

The same result also occurs using the first-differenced yield data (Figure 3). This finding indicates that the term structure data used are relevant for analysis through the decomposition method. Furthermore, three factors appear to be sufficient to explain the variations in the term structure. The first three principal components can account for $99.2 \%$ of the variance in the level-form data and $98.5 \%$ of the variance in the first-differenced form data (Table 1). Then, regression with 3 factors can explain the variation of yield on each maturity well, as indicated by the relatively small standard deviation of the residual (Table 2).

The Dynamic Nelson-Siegel model components show the contribution of each yield curve component for each maturity. The level component shows the same effect for each maturity, the slope component represents a larger contribution to short-term maturity, while the curvature component represents a larger contribution to medium-term maturity.

The main results of the DNS model estimate are the level, slope and curvature components for each period 


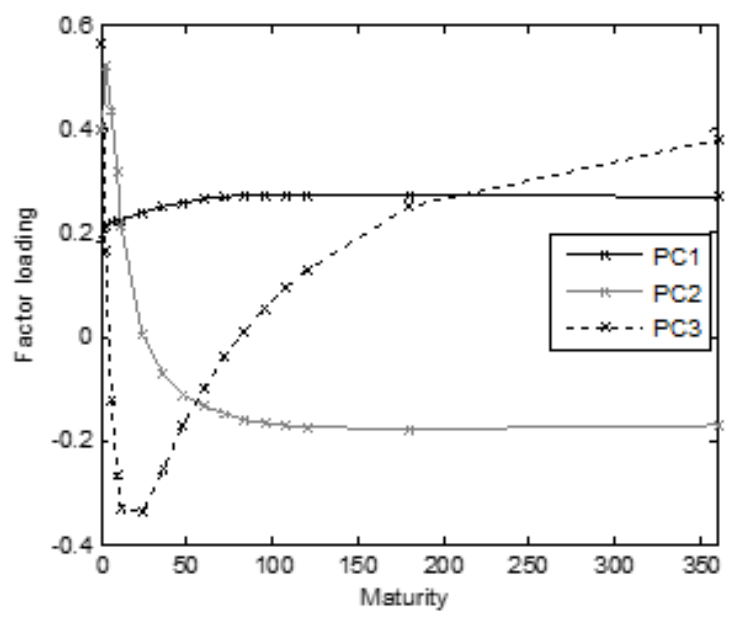

Figure 2. The first three principal components of the yield.

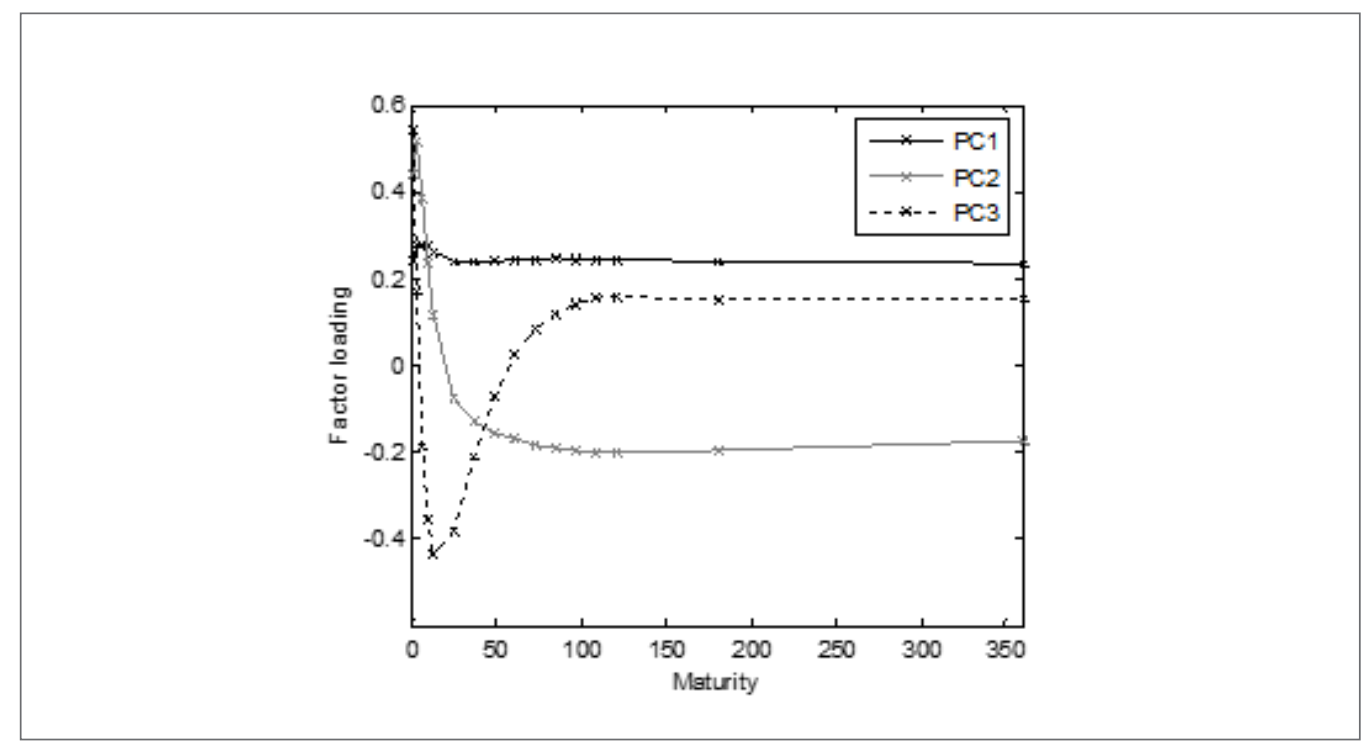

Figure 3. The first three principal components of the difference yield. 
Table 1. Percentage of Principal Components Explained Variance

\begin{tabular}{lrccc}
\hline Principal components & \multicolumn{2}{l}{ Level } & Difference \\
& $\begin{array}{l}\text { \% variance } \\
\text { explained }\end{array}$ & cumulative & $\begin{array}{l}\text { \% variance } \\
\text { explained }\end{array}$ & cumulative \\
\hline PC1 & 91.87 & 91.87 & 80.37 & 80.37 \\
PC2 & 5.25 & 97.12 & 15.72 & 96.09 \\
PC3 & 2.09 & 99.21 & 2.39 & 98.48 \\
PC4 & & & & 9.76
\end{tabular}

Table 2. Standard Deviation Level and Residual over 3 Factors Regression Model

\begin{tabular}{|c|c|c|}
\hline Maturity (months) & Level standard deviation & $\begin{array}{l}\text { Residual standard deviation for } 3 \\
\text { factors model }\end{array}$ \\
\hline 1 & 1.64 & 0.29 \\
\hline 3 & 1.77 & 0.16 \\
\hline 6 & 1.75 & 0.15 \\
\hline 9 & 1.70 & 0.14 \\
\hline 12 & 1.69 & 0.16 \\
\hline 24 & 1.74 & 0.17 \\
\hline 36 & 1.81 & 0.15 \\
\hline 48 & 1.87 & 0.14 \\
\hline 60 & 1.90 & 0.13 \\
\hline 72 & 1.93 & 0.12 \\
\hline 84 & 1.94 & 0.10 \\
\hline
\end{tabular}


Table 2. Standard Deviation Level and Residual over 3 Factors Regression Model (Continued)

\begin{tabular}{lll}
\hline Maturity (month) & Level standard deviation & $\begin{array}{l}\text { Residual standard deviation for } 3 \\
\text { factors model }\end{array}$
\end{tabular}

of observation. If each component is substituted in the DNS equation to obtain the real interest rate estimation for each maturity, it will be able to form a fitted yield curve. As illustrated at one time period in Figure 4, the real fitted curve can illustrate the real yield distribution between maturities well.

A positive level component indicates that, if we consider all the maturities along the yield curve, Indonesia's real interest rate is always positive throughout the observation period. However, real interest rates appear to have declined after the global financial crisis, in line with rising global investor risk appetites. The slope component, which always has a negative value, indicates that the yield curve for Indonesia always has a positive slope, except at one observation point.

Furthermore, the negative curvature value indicates a relatively low medium-term yield formed by the slope component, indicating a low additional term premium on longer maturities. However, the value of curvature tends to increase since 2014, which indicates that the yield curve is likely to have a hump in the medium-term tenor (as illustrated in Figure 6). The upward trend in the curvature indicates an increase in medium-term yield relative to other maturities, which can be attributed to several things, including the following: 1. increased investor preference for investments with shorter horizons than before, which can also occur due to increasing expectations of risk on medium-term horizons; 2 . expectations of an interest rate increase in the shorter term; and 3. the existence of market imperfections, which can be caused by a reduced supply of bonds for medium-term maturity.

From the estimation result of the DNS model, it can also be seen that $\mu_{L}=0.037$ and $\mu_{S}=0.031$. This indicates that, along the observation period, the average longterm interest rate in real terms is $3.7 \%$, while the shortterm average rate in real terms is $0.6 \%$ (obtained from $\left.\mu_{L}-\mu_{S}\right)$. The large difference indicates an average yield curve that is upward sloping and relatively steep. The steep and upward sloping form may indicate the following: 1 . a relatively high risk premium on longer maturities (as per the liquidity premium hypothesis); and 2. on average in the period of observation, there is an expectation of rate hikes or an implicit inflation risk (according to the expectations hypothesis)

State-space estimation results for the natural yield curve with Indonesian data are generally in line with the estimation results for Japanese data of Imakubo et al. (2018). The estimation parameters can be interpreted further by considering equation (6), which directly illustrates the relationship of output gap and each yield curve component.

The estimation results show that the curvature gap is the most significant component affecting the output gap, followed by the level gap $\left(b_{C}<b_{L}<b_{S}\right)$. This shows that, historically, the gap between the medium-term real yield and the natural yield curve has the highest influence on Indonesia's output gap, compared to the gap in the real yield with long maturity, as well as the gap between the real and natural yield with short-term maturity. 


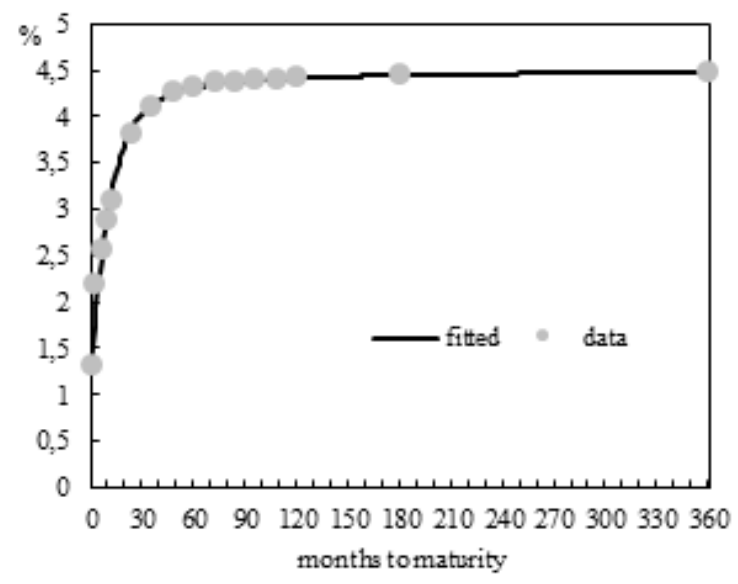

Figure 4. Real interest rate and fitted estimation, December 2015 position.

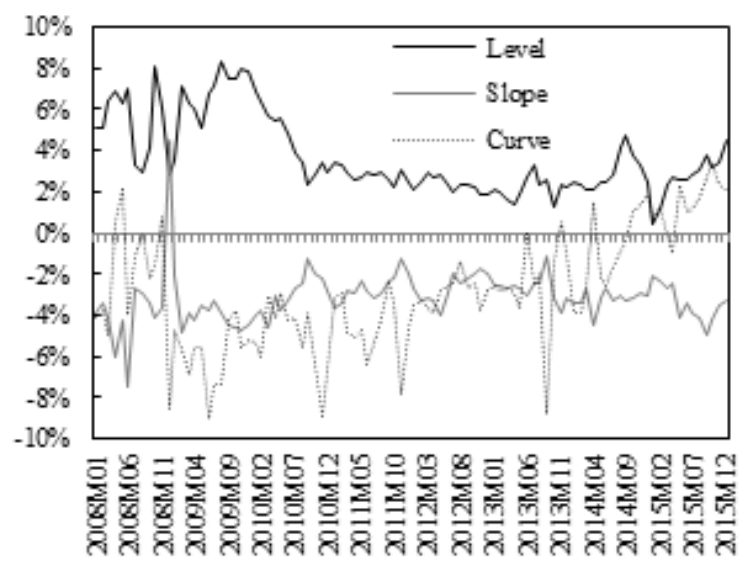

Figure 5. Estimated real yield curve component results. 


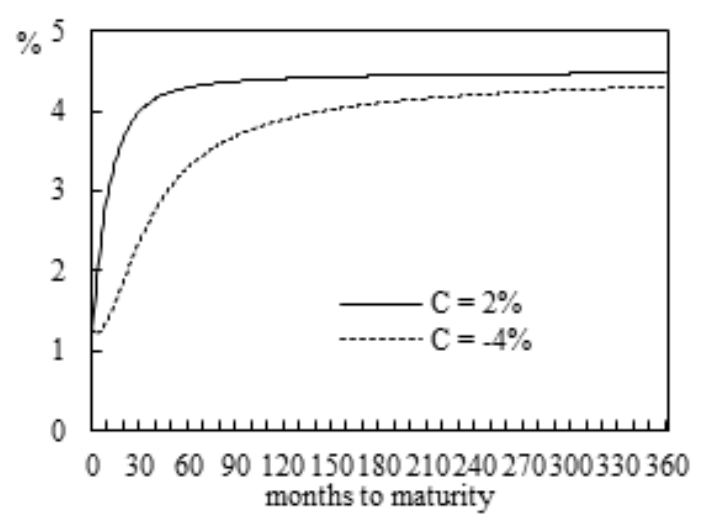

Figure 6. Impact illustration of curvature change, $-4 \%$ to $2 \%$.

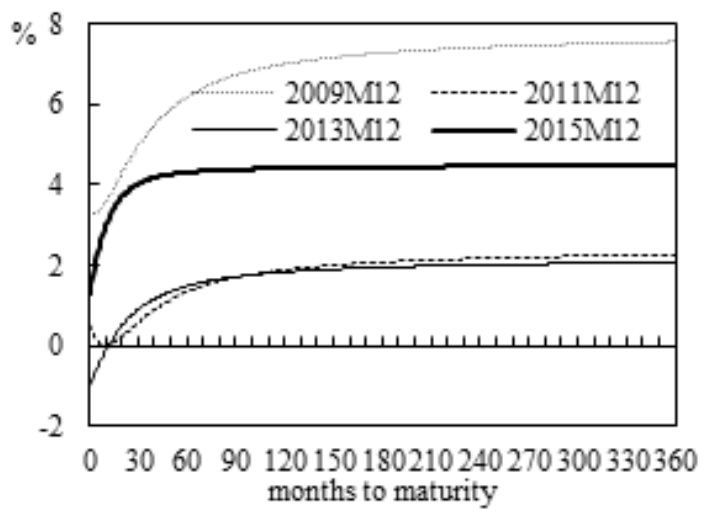

Figure 7. Real yield curve changes in multiple periods. 
Table 3. Estimation Results of Natural Yield Curve

\begin{tabular}{|c|c|c|}
\hline Parameter & Indonesia & Japan \\
\hline$a_{y}$ & 0.706 & $0.924^{* * *}$ \\
\hline$b_{L}$ & $-0.050^{* * *}$ & $-0.215^{* * *}$ \\
\hline$b_{s}$ & $-0.019 * * *$ & $-0.117^{* * *}$ \\
\hline$b_{c}$ & $-0.050^{* * *}$ & $-0.045^{* * *}$ \\
\hline$a_{L}$ & $0.809^{* * * *}$ & $0.847^{* * *}$ \\
\hline$g_{y L}$ & $0.048^{* * *}$ & $0.061^{* * *}$ \\
\hline$a_{s}$ & $0.844 * * *$ & $0.844 * * *$ \\
\hline$g_{y s}$ & $0.068^{* * *}$ & $0.064^{* * *}$ \\
\hline$a_{c}$ & $0.395^{* * *}$ & $0.893^{* * *}$ \\
\hline$g_{y c}$ & $0.060^{* * *}$ & 0.059 \\
\hline$h_{y L}$ & 0.965 & $0.921^{* * *}$ \\
\hline$h_{y s}$ & -0.207 & -0.318 \\
\hline$h_{L S}$ & -0.182 & -0.291 \\
\hline$h_{y c}$ & -0.215 & -0.032 \\
\hline$h_{L C}$ & -0.416 & -0.906 \\
\hline$h_{S C}$ & -0.415 & -1.371 \\
\hline \multicolumn{3}{|l|}{ States } \\
\hline Level & $0.033^{*}$ & NA \\
\hline Slope & $-0.027^{*}$ & NA \\
\hline Curvature & 0.014 & NA \\
\hline
\end{tabular}

Note: Parameters on Indonesia are generated on estimation in this study, while parameters on Japan is the estimation result of Imakubo et al (2018). ${ }^{* * *, * *},{ }^{*}$ denotes significance in $99 \%, 95 \%$, and $90 \%$ confidence level, respectively 
Some other estimation parameters indicate that the model is stable (Table 3). For example, the $a_{y}$ parameter is an autoregressive component of the output gap, so the estimation result where $0<a_{y}<1$ indicates the stability of the process. Likewise, in $a_{L}, a_{S}$, and $a_{C}$, each of which is an autoregressive process parameter for the level, slope, and curvature components, estimated coefficients between 0 and 1 indicate a stable meanreverting process.

Across time periods, the estimated factor loadings (level, slope, and curvature components) of real interest rates move around the estimated factor loadings of natural interest rates. This is consistent with the movement of the output gap in general with a zero long-term average. In other words, the potential output is the trend of actual output.

The level component of the natural yield curve was rising during the global financial crisis, which indicates an increase in natural yield in all maturities. Then, the level component gradually decreases until the end of 2013, thus indicating a gradual decrease in natural yield across all maturities. Furthermore, the increase in natural yields across all maturities temporarily occurs during the tapering-off period in 2014.

The slope component looks relatively stable throughout observations from 2008 to 2015 . Thus, it can indicate several things, including the following: 1 . variations that occur in short-term interest rates relative to other maturities do not play an important role for the movement of output gaps in the long term; 2. variations that occur in short-term interest rates are corrective of the output gap in short maturities, which can occur given that short-term interest rates are the operational goals of monetary policy aimed at macroeconomic stability; and 3. the main thing that affects the output gap is the yield for longer maturities, which, according to Obstfeld (2014), occurs because of the external vulnerability of a small open economy with a flexible exchange rate regime.

In contrast to the other two components, the curve component declined during the global financial crisis and then gradually increased until the end of 2015. This

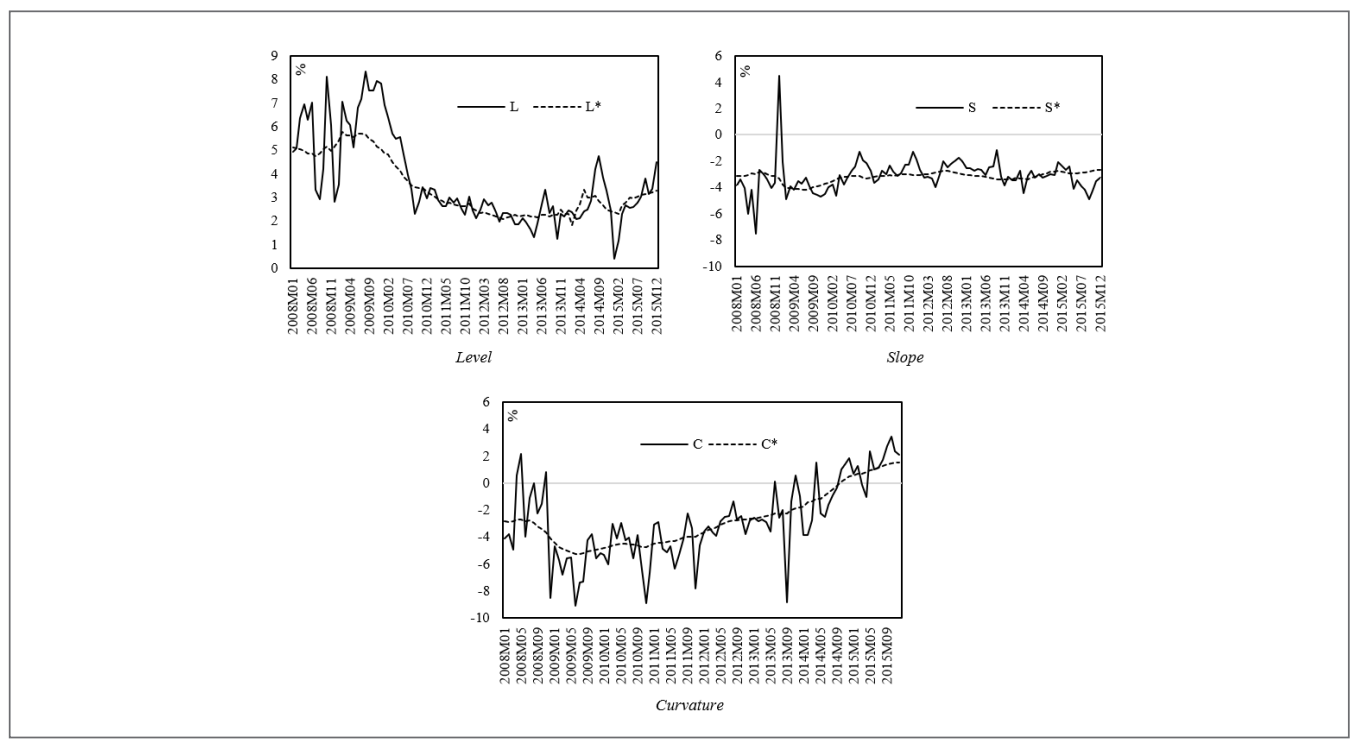

Figure 8. Components of real and natural yield curves. 
finding indicates the gradual increase in the natural yield on mid-term maturities by the end of 2015 .

The trend of all natural yield curve components in the medium term tends to be in line with the corresponding real yield curve component. There is a gradual decline in the level component during the global financial crisis. The slope component tends to be constantly in the negative zone, which indicates that the natural yield curve is always upward sloping and that the premium term always rises as the maturity increases. The curvature component is negative, which indicates an additional downward bend of the yield curve. However, it became positive since late 2014, which indicates a higher hump in the medium-term yield.

Between the yield curve components, the gaps between the real yield and the natural yield are not necessarily correlated. For example, during the global financial crisis, the level gap and curvature gap are in positive zones. This indicates that, to achieve a minimum output gap, it is necessary to decrease all yields for each maturity, as well as decrease the medium-term yield relative to other maturities. In a policy context, this can be interpreted as lowering policy rates, com- bined with some purchases on assets that will mature in the medium term.

Using the estimated factor loadings of the natural yield curve, the natural yield on each maturity can be obtained via equation (3). The resulting natural yield curve is illustrated in Figure 11. Therefore, it can indicate the interest rate gap in each maturity.

As external shock occurred during the global financial crisis, the natural yield curve became steeper, whereas the difference in the natural interest rate across maturities widened. The natural yield curve after the global financial crisis declined gradually, and the difference in interest rates across maturities narrowed slightly. At the time of the tapering off during 2013/2014, the interest rate difference across tenors widened once more.

The graphs below show some examples of the real yield curve gap and natural yield curve. In October 2013, when the monetary tightening cycle began, the real yield curve appeared to be lower than the natural yield curve, so that the benchmark interest rate needs to be raised to contract the output gap. In December 2013, when the policy stance did not change, the real

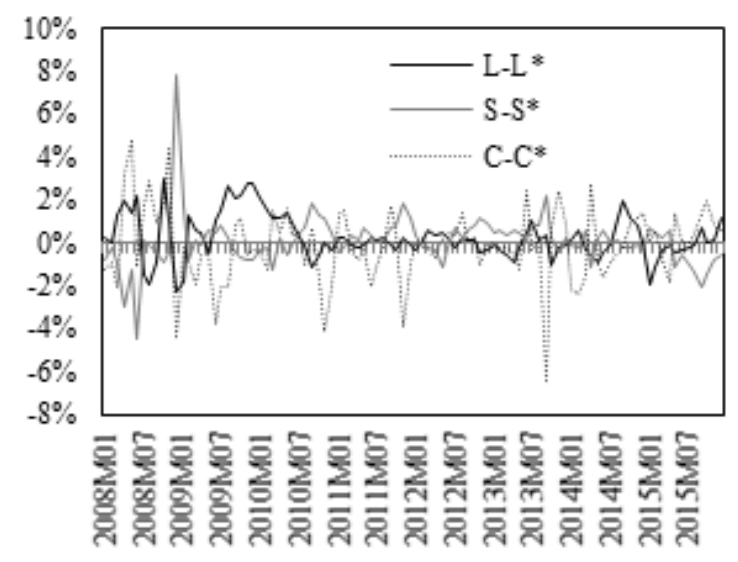

Figure 9. Gap of real and natural yield curves, by components. 


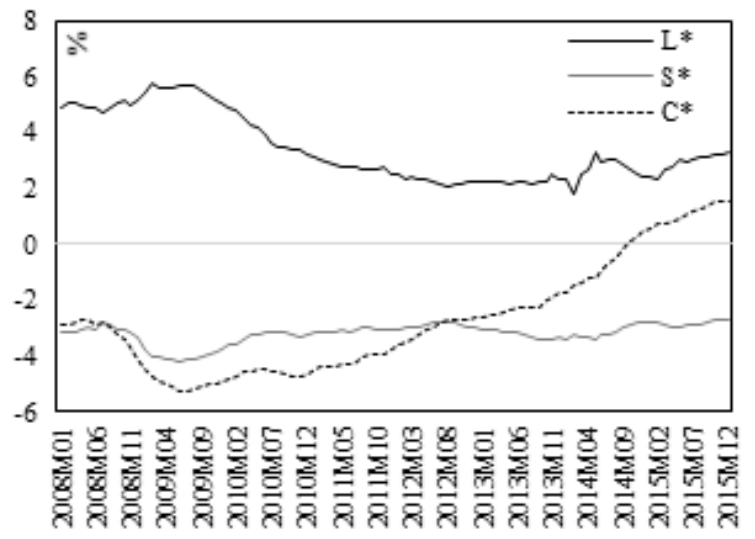

Figure 10. Estimated components of natural yield curve.

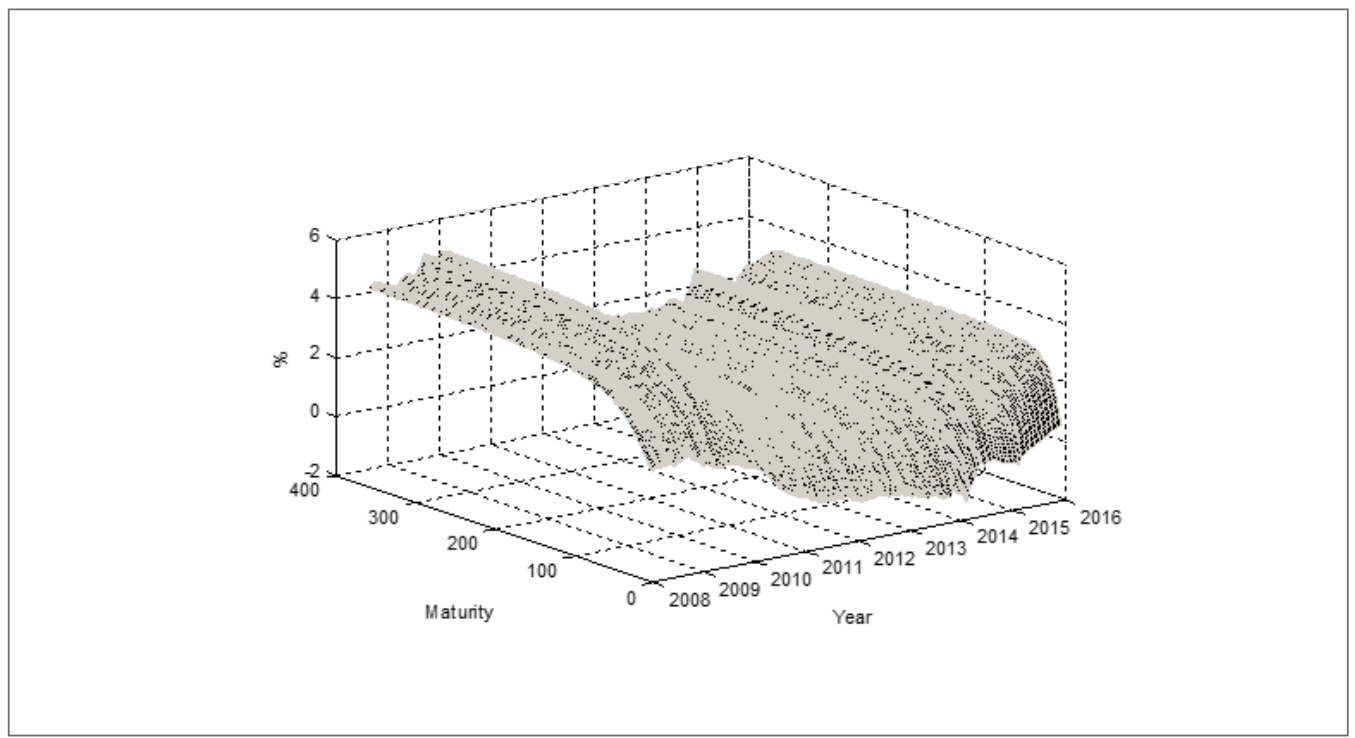

Figure 11. Estimated components of natural yield curve. 

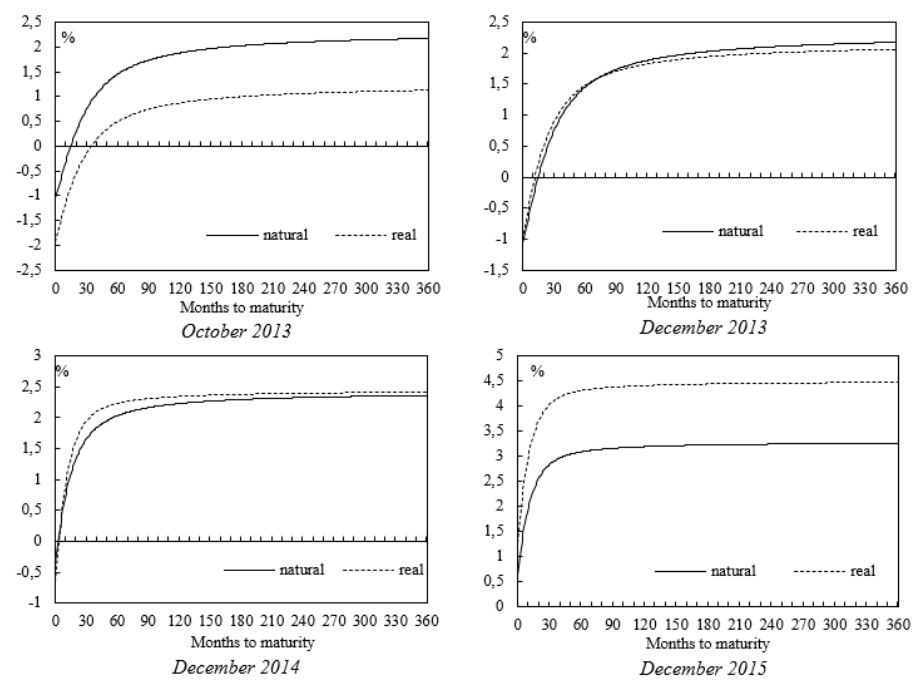

Figure 12. Natural and real yield curves on some selected dates.

yield curve appeared to coincide with the natural yield curve. In December 2014, there is no obvious indication of required policy rate changes, but the curvature difference may suggest some purchases on assets that will be matured in the medium term. Then, in December 2015, when the loosening cycle is about to start, the real yield curve lies higher than the natural yield curve, which indicates that the yield curve needs to be lowered to narrow the output gap. In addition, there is some difference in slope between the real and natural yield curves, which indicates some necessary purchase or sale of assets on some particular maturities to match the natural yield curve.

\section{Concluding Remarks}

This research calculates the natural yield curve for Indonesia. The estimation was carried out by adopting the Imakubo et al. (2018) method (i.e., by estimating Dynamic Nelson-Siegel according to Diebold et al. (2006)), and the natural yield curve was estimated. Both stages are done through state-space modeling with a Kalman filter. The estimation results are fairly consistent with the existing hypotheses, including the results of Imakubo et al. (2018). In addition, the study also confirmed the applicability of the Nelson-Siegel model to Indonesia through a principal components analysis.

The main contribution of this research is the result of the estimation of the natural yield curve for the Indonesian case. In other words, the study provides an overview of the natural yield rate for each maturity in the observation period (i.e., for the time span from 2005 to 2015). Some other findings in this study include the following: 1. Approximately 99\% of Indonesia's yield curve variation can be explained by the first three principal components that are shaped similarly to the level, slope and curvature components; 2 . The natural yield curve of Indonesia always has a positive slope at all times; 3. Medium-term yields are the maturities with the highest influence on Indonesia's output gap; 4. Natural yield curve movements are in line with global economic developments; 5. Historically, a tight monetary policy stance is indicated when the natural yield curve lies below the real yield curve, while a loose monetary policy is indicated when the natural yield curve lies above the real yield curve.

The estimation of the natural yield curve can be used as one of the considerations for monetary policy 
formulation aimed at achieving macroeconomic stability by directing the output gap to a minimum level, as well as indicating the implications of external shocks in influencing the stability of the economy. As the natural yield curve implies that the natural rate of interest varies across maturities, it indicates a more detailed suggestion for monetary policy. In the operational context, the estimation of the natural yield curve can also be used as guidance for monetary operation in every maturity, considering that real yield and natural yield gap can be indicated in every maturity. Moreover, the stronger influence of medium- and long-term yields on output gap indicates that a policy that solely relies on a benchmark interest rate is insufficient. A policy mix is needed to achieve macroeconomic stability. For further discussion on this approach, see Warjiyo and Juhro (2019).

In accordance with the scope and limitations of this study, areas for further research includes a supply-demand analysis (the existence of market imperfections) between maturities aimed at determining the cause of different influences between maturities on the output gap; Another discussion to consider is related to monetary operation and communication strategies and look for opportunities to neutralize external shocks on the level and slope components of yield curve.

\section{References}

Amato, J. D. (2005). The role of the natural rate of interest in monetary policy, CESifo Economic Studies, 51(4), 729-755.

Basdevant, O., N. Björksten \& Ö. Karagedikli (2004). Estimating a time varying neutral real interest rate for New Zealand. Discussion Paper DP2004/01. Reserve Bank of New Zealand.

Blinder, A. S., M. Ehrmann, M. Fratzscher, J. De Haan, \& D. Jansen (2008). Central bank communication and monetary policy: A survey of theory and evidence. Journal of Economic Literature 46(4), 910-945

Brzoza-Brzezina, M., \& Kotłowski, J. (2014). Measuring the natural yield curve. Applied Economics, 46(17), 2052-2065.

Christensen, J. H. E., Diebold, F. X. \& Rudebusch, G. D. (2009). An arbitrage-free generalized Nelson-Siegel term structure model. Econometrics Journal, 12(3), C33-C64.

Cochrane, J. H., \& Piazzesi, M. (2005). Bond risk premia. American Economic Review, 95(1), $138-160$.

Diebold, F. X., \& Li, C. (2006). Forecasting the term structure of government bond yields. Journal of econometrics, 130(2), 337-364.

Diebold, F. X., Rudebusch, G. D., \& Aruoba, S. B. (2006). The macroeconomy and the yield curve: a dynamic latent factor approach. Journal of econometrics, 131(1-2), 309-338.

Djuranovik, L. (2014). The Indonesian macroeconomy and the yield curve: A Dynamic Latent Factor Approach. Journal of Asian Economics, 34, $1-15$.

Duffee, G. R. (2002). Term premia and interest rate forecasts in affine models. Journal of Finance, 57(1), 405-443.

Duffie, D., \& Kan, R. (1996). A yield-factor model of interest rates. Mathematical finance, 6(4), 379-406.

Harahap, B. A., Maryaningsih N., Panjaitan, L. N., \& Satyanugroho, R. (2013). Revisiting transmisi suku bunga kebijakan moneter: Pendekatan FAVAR [Revisiting transmission of monetary policy rate: FAVAR approach]. Working Paper. Bank Indonesia, 1-37.

Harahap, B. A., Triswati, F. I. \& Khasananda, R. (2014). Kajian penentuan term structure suku bunga pasar uang [Determining term structure of money market rate]. Working Paper. Bank Indonesia, 1-41.

Harahap, B. A., Bary, P., Panjaitan, L.N., \& Satyanugroho, R. (2016). Spillovers of United States and People's Republic of China shocks on small open economies: The case of Indonesia. ADBI Working Paper 616. Asian Development Bank Institute.

Imakubo, K., H. Kojima, \& J. Nakajima (2018) The natural yield curve: Its concept and measurement, Empirical Economics, 55, 551-572.

Kim, D. H., \& Orphanides, A. (2007). The bond market term premium: what is it, and how can we measure it?. BIS Quarterly Review, 27-40

Laubach, T. \& Williams, J.C. (2003). Measuring the natural rate of interest. Review of Economics and Statistics, 85(4), 1063-1070.

Nelson, C. R. \& Siegel, A. F. (1987). Parsimonious modeling of yield curve. Journal of Business 60, 473-489.

Nugroho, W. A., \& Mochtar, F. (2006). Suku bunga natural di Indonesia: Temuan awal dan beberapa analisis lanjutan [Natural interest rate in Indonesia: Preliminary findings and further 
analysis]. Working Paper, Bank Indonesia, 1-35.

Obstfeld, M. (2014). Trilemmas and trade-offs: Living with financial globalisation. BIS Working Papers 480, https://www.bis.org/publ/work480. pdf

Orphanides, A., \& Williams, J. C. (2007). Robust monetary policy with imperfect knowledge. Journal of Monetary Economics 54(5), 14061435.

Rey, H. (2013). Dilemma not Trilemma: The Global Financial Cycle and Monetary Policy Independence. Proceedings, Jackson Hole, 1-2.

Schoenmaker, D. (2011). The financial trilemma. Economics letters, 111(1), 57-59.

Söderlind, P., \& Svensson, L. (1997) New Techniques to Extract Market Expectations from Financial Instruments. Journal of Monetary Economics 40: 383-429.

Svensson, L. E. (1995). Estimating forward interest rates with the extended Nelson \& Siegel method. Sveriges Riksbank Quarterly Review, 3(1), $13-26$.

Warjiyo, P., \& Juhro, S. M. (2019). Central Bank Policy: Theory and Practice. 1st edition. Emerald Publishing.

Wimanda, R. E., Wibowo, W. A., \& Idham (2013). Natural rate of interest in Indonesia: Kalman Filter Approach. Jurnal BPPK: Badan Pendidikan Dan Pelatihan Keuangan, 6(1): 49-60.

\section{Endnotes}

The views expressed in this paper are those of the authors and do not necessarily represent the views of Bank Indonesia. 